\title{
CAPACIDADE REPRODUTIVA DE Poropbyllum ruderale (Jacq.) Cass.
}

\author{
G. DE MARINIS*, A. LEPOS**, L.P. FRIEBOLIN** \& R.A.M. MUSA**
}

\section{RESUMO}

Uma população de Porophyllum ruderale (Jacq.) Cass. ocorrente nos arredores de São Josê do Rio Preto (SP) foi estudada quanto à estatura, biomassa epígea seca, número de ramos, de capítulos por ramo e por indivíduo e quanto à producão de aquênios por capítulo e por indivíduo. Es ta última foi relativamente baixa (média de 2510 aquênios) correspondendo, na base de $80 \%$ de germinabilidade, à média de 2008 disseminulos viá veis por indivíduo. Esta capacidade reprodutiva é muito superior ao número de indivíduos que habitualmente ocorrem em condições naturais. A fraca densidade populacional característica da espécie deve ser atribuída, portanto, a outros fatores, tais como, possivelmente, as condições do solo, a competicão interespecífica e, talvez, a acão de inimigos naturais. A produção individual de capítulos e de aquênios revelou correlação com a estatura e a biomassa mas o número de aquênios por capítulo (53 em média) não revelou correlacão com a estatura, a biomassa e a produção individual de capítulos e de aquénios, demonstrando ser um carater pouco afe tado pelo vigor vegetativo.

\section{UNITERMOS:}

Malerbologia, Capacidade reprodutiva, Porophyllum ruderale (Jacq.) Cass.

\section{SUMMARY}

REPRÓDUCTIVE CAPACITY ÓF Poro phyllum ruderale (Jacq.) Cass.

A population of Porophyllum ruderale (Jacq.) Cass., a weed of the Compositae family, occurring in a fallow area near São Jose do Rio Preto (State of São Paulo, Brazil) was studied in regard to: a) height, b) dry epigeous biomass, c) number of branches, d) number of heads per branch, e) number of heads per plant, f) number of achenes per head and g) output of achenes per plant. This output was relatively low (on an average of 2510) corresponding to 2008 viable achenes per plant, taking into account a germination percentage of $80 \%$. The observed reproductive capacity is very higher than the number of mature in dividuals usually found in the field and does not explain, therefore, the widely scattered distribution of $P$. ruderale. Environmental factors, possi-
* Professor-Titular, Departamento de Botânica, Instituto de Biociências, Universidade Estadual Paulista <<Júlio de Mesquita Filho>>, 13.500 Rio Claro, SP.

** Ex-extagiárias da Faculdade de Filosofia, Ciências e Letras de São José do Rio Preto (nova denominação: Instituto de Biociências, Letras e Ciências Exatas, UNESP).

Recebido para publicação em 15/05/80

bly soil conditions, interspecific competition and natural enemies, should be taken into account. The number of heads and achenes per plant showed correlation with height and biomass, while the number of achenes per head (on an average of 53) showed no correlation with height, biomass and number of heads and achenes per plant, revealing to be a character little affected by vegetati ve vigours.

KEYWÓRDS:

Weed Biology, Reproductive capacity, Porophyllum ruderale (Jacq.) Cass.

\section{INTRODUÇÃO}

O conhecimento da capacidade reprodutiva das malerbas propicia me lhor compreensão de seu papel ecológico e contribui, portanto, para o aperfeiçoamento de seu controle. Infelizmente, este assunto não foi ainda suficientemente estudado no Brasil, sendo escassos os trabalhos a respeito; entre eles, há os que foram realizados sobre Bidens pilosa L. (De Marinis, 10), Cenchrus echinatus L. (Pacheco \& De Marinis, 18) e Melancium campestre Naud. (Cesar \& De Marinis, 6).

O presente trabalho visa fornecer informaçôes a respeito da capacidade reprodutiva de Porophyllum ruderale (Jacq.) Cass. e das correlaçôes existentes entre alguns parâmetros vegetativos e reprodutivos da planta.

$P$. ruderale pertence à familia Compositae e, embora não esteja citado na 12. ${ }^{a}$ edição do Syllabus de Engler (Wagenitz, 21) se enquadra, pelos seus caracteres, na subfamilia Asteroideae, tribo Helenieae, subtribo Tagetinae.

E planta herbácea erecta anual, fétida, que pode alcançar dois metros de altura (Löfgren \& Everett, 16). No que 
se refere à forma biológica deve ser incluída entre as terófitas de Raunkiaer (19) porque, sendo anual e não dispondo de meios de propagação vegetativa, depende dos dissemínulos reprodutivos para sua manutenção e dispersão. Os dissemínulos são aquênios cuja descrição se encontra em Baker (3); pertencem, do ponto de vista ecomorfológico, ao tipo pogonócoro de Dansereau e Lems (Dansereau, 7) e possuem um papilho bem desenvolvido, composto de 50 ou mais cerdas flexuosas e ciliadas (Baker, 3).

A planta é conhecida no Brasil como couve-cravinho (Angely, 1; Blanco, 4; Kuhlmann \& Kühn, .14; Leitão F. ${ }^{\circ}$ et al. , 15; Löfgren \& Everett, 16), erva-fresca (Angely, 1; Blanco, 4; Leitão $\mathrm{F}$. $^{\circ}$ et a1., 15; Löfgren \& Everett, 16), couvinha, erva-couvinha, cravo-de-urubu (Blanco, 4). O comportamento infestante da espécie, já consignado em seu epíteto especifico por Jacquin em 1760, é mencionado para o Brasil por numerosos autores (Baker, 3; Blanco, 4; Carvalho, 5; Dedecca, 8; De Marini s, 11; Gem tchúj nic ov, 12; Leitão F. et al., 15; Monteiro et al., 17; Warming, 22); trata-se de espécie principalmente ruderal (Blanco, 4; Leitão $\mathrm{F}^{\circ}{ }^{\circ}$ et al., 15) pouco frequente e levemente nociva (Blanco, 4).

\section{MATERIAIS E MÉTODOS}

Foram estudados 120 indivíduos espontâneos, localizados nos arredores da cidade de São José do Rio Preto (SP) e todos no estágio de frutificação.

De cada indivíduo foram medidos: estatura (e), número de ramos (r/i), número de capítulos por ramo $(c / r)$, número de aquênios por capítulo $(a / c)$ e biomassa epígea seca em estufa a $105: 110^{\circ} \mathrm{C}$ até peso constante (Bes ). Foram calculados o número de capítulos por planta (c/i) e o número de aquénios por planta (ali). A correlação entre alguns destes parâmetros foi calculada pelos métodos estatísticos usuais.

Para verificar a germinabilidade, aquênios retirados dos indivíduos em estudo foram colocados em placas de petri fechadas, sobre papel de filtro úmido, e mantidos em condições de laboratório, à temperatura entre $22^{\circ} \mathrm{C} \mathrm{e} 26^{\circ} \mathrm{C}$, durante trinta dias. fórmula:

A capacidade reprodutiva foi calculada pela

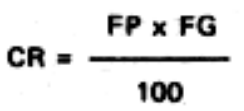

onde FP é o número de frutos produzidos por cada indivíduo e FG é o número de aquênios germinados no respectivo teste, sobre o total de 100 .

\section{RESULTADOS E DISCUSSÃO}

O número médio de aquênios por capítulo $(\mathrm{a} / \mathrm{c})$ foi de 53 e o número médio de aquênios por individuo foi de 2510 .

Os aquênios retirados de capítulos bem abertos chegaram a mostrar 98\% de germinabilidade. Para o cálculo da capacidade reprodutiva foi utilizado o valor médio de $80 \%$, que levou à capacidade reprodutiva média de 2008 aquênios viáveis por indivíduo.

A existência ou não de correlação entre alguns dos parâmetros estudados é indicada no quadro 1 .

Quadro 1. Correlação entre alguns parâmetros de $P$. ruderale.

\begin{tabular}{llllll}
\hline \hline & $e$ & c/i & a/c & a/i & Bes \\
\hline c & - & 0,76 & 0,12 & 0,63 & 0,54 \\
\hline$c / i$ & 0,76 & - & 0,09 & 0,88 & 0,41 \\
\hline a/c & 0,12 & 0,09 & - & 0,14 & 0,07 \\
\hline a/ 1 & 0,63 & 0,88 & 0,14 & - & 0,59 \\
\hline Bes & 0,54 & 0,41 & 0,07 & 0,59 & - \\
\hline
\end{tabular}

Limites de significância de $r$ para G.L. $=118$

$S \%: r=0,180 ; 1 \%: r=0,235$

e = estatura; $\quad$ fi $=$ número de capitulos por indivíduo; a/c = número de aquênios por capitulo; $\mathbf{a} / \mathrm{i}=$ número de aquênios por indivíduos; Bes = biomassa cpígea seca.

OBS.: Os valores de $r$ foram obtidos por interpolação da tábua de Snedecor (G.W. Snedecor, Métodos estatísticos aplicados à experimentação agrícola e blológica. Lisboa , 1945. Tab. 7.2. pág. 156).

Houve correlação entre estatura, de um lado, e número de aquênios por indivíduo e biomassa, do outro, de tal modo que a estatura pode ser tomada como um indice desses dois parâmetros, de primordial importância para a agressividade da planta. E fato já bem conhecido (De Marinis, 9) que existe geralmente boa correlação entre a intensida de do crescimento em altura e o peso da planta.

Não houve correlação entre o número de aquênios por capítulo, de um la- 
do, e todos os parâmetros estudados, do outro, confirmando que a composição numérica do capítulo é determinada geneticamente e independe dos fatores externos que agem sobre os demais parâmetros.

A capacidade reprodutiva verifica da, embora não seja das maiores, pare ce mais do que suficiente para ass egu rar uma intensa propagação, a qual, porém, não costuma ocorrer nos casos concretos. A distância considerável entre os indivíduos estudados não permitiu um cálculo satisfatório do número de dissemínulos por área, número que, segundo Harper (13) constitui o parâmetro mais vital envolvido na dinâmica das populaçôes anuais. É evidente, porém, que tal número, no caso aqui estudado, deve ser muito pequeno, concordando com a costumeira escassez da espécie. Esta escassez deve ser atribuída as características e condiçôes do solo e, possivelmente, ao grau de competição interespecífica (Ashby, 2; Salisbury, 20); não se pode excluir a priori a ação de inimigos naturais.

A estatura apresentou correlação com a biomassa e com o número de aquênios por indivíduo, revelando-se como um bom indice do vigor vegetativo e da capacidade reprodutiva. O número de aquênios por capítulo, ao contrário, não demonstrou correlação com os outros parâmetros estudados, revelando-se como pouco afetado pelo vigor vegetativo e sem grande influência sobre a capacidade reprodutiva da planta.

\section{BIBLIOGRAFIA}

I. Angely, J. Flora analitica e ntogeografica do Bstado de Sáo Paulo, 5.0 vol., 1.a ed. Sảo Paulo, Ediçóes Phyton, 1970.

2. Ashby, M. Introduction to Plant Ecology. London, Melbourne, Toronto, McMillan, 1965.

3. Baker, J.G. Compositae, IV. In: Martii Flora Brasiliensis, VI (III), Monachil, 1884.

4. Blanco, H.G. Catálogo das espécles de mato infestantes de areas cultivadas no Brasil. Familia do picáo-preto (Compositae). O Biológico, 42(3-4): 62-97, 1976.
5. Carvalho, L.F. de. Plantas invasoras de culturas no Estado do Rlo de Janeiro. Seminário Brasileiro de Herbicidas e Ervas Daninhas, 2.' Rio de Janeiro, 1959. Anais, p.115-123.

6. Cesar, O. e De Marinis, G. Propagaçáo vegetativa e capacidade reprodutiva de Melancium campestre Naud. Revista de Agricultura, 53 (4): 205-208, 1978.

7. Dansereau, P. Biogeography: an ecological perspective. New York. The Ronald Press Company, 1957.

8. Dedecca, D.M. Plantas invasoras de cafezais. Agricultura e Pecuária, 30(432): 40-42, 1959.

9. De Marinis, G. Ecologia das plantas daninhas In: Camargo, P.N. (Coord.) Texto básico de controle quimico de plantas daninhas. $3 .^{\mathrm{a}} \mathrm{ed}$. ampl. e ilustr. Escola Superior de Agricultura "Luiz de Queiroz", USP. Piracicaba (mimeografado). 1971.

10. De Marinis, G. Nota sobre a capacidade reprodutiva de Bidens pilosa L. Revista de Agricultura, 48(2-3): 95-100, 1973.

11. De Marinis, G. Catálogo brasileiro de plantas daninhas da familia Compositae: 2, a parte. Ciência e Cultura, 25(6, supl.): $327,1973$.

12. Gemtchújnicov, I. Chave artificial para identificaçáo de plantas daninhas do Estado de Sâo Paulo. Faculdade de Ciências Médicas e Biológicas de Botucatu (mimeografado), 1968.

13. Harper, J.L. Factors controlling plant numbers. In: J.L. Harper (ed.). The Biology of Weeds: 119-132. Oxford, Blackwel Scientific Publications, 1960.

14. Kuhlmann, M. e Kūhn, E. A fora do distrito de Ibiti (ex-Monte Alegre), municipio de Amparo. Instituto de Botánica, Sảo Paulo, 1947.

15. Leitâo $F^{\circ}, H$. de $F$., Aranha, C. e Bacchi, $O$ Plantas invasoras de culturas no Estado de São Paulo. Vol. II. Sâo Paulo. Hucitech, 1975.

16. Löfgren, A. e Everett, H.L. Analysis de plantas. Sáo Paulo, Typografia e Papelaria de Vanorden \& Co., 1905

17. Monteiro F.o, H. Paixão, J.C. e Monteiro J.M Plantas herbáceas invasoras de cultivos. Seminário Brasileiro de Herbicidas e Ervas Daninhas, $1^{\circ}$, Rio de Janeiro, 1956. Anais, p.157169.

18. Pacheco, R.P.B. e De Marinis, G. Primeiras investigaçóes de malerbecologia na região $\mathrm{Su}$ doeste do Estado de São Paulo. Congresso de la Asociación Latinoamericana de Malezas, 3. Mar del Plata, 1976. Trabajos y Resúmenes, p. I: 67-72.

19. Raunkiaer, C. The life forms of plants and statistical Plant Geography (trans. H.G. Carter et al.). Oxford, Clarendon Press. 1934

20. Salisbury, E.J. The reproductive capacity of plants. London, G. Bell \& Sons Ltd., 1942.

21. Wagenitz, G. Campanulales. In: A. Engler's Syllabus der Planzenfamilien, zwölfte Auf., Berlin-Nikolassee, 1964.

22. Warming, E. Lagoa Santa. Contribuiçáo para a geographia phytobiológica. (trad. A. Loefgren), Bello Horizonte. Imprensa Official de Minas Geraes, 1908. 